\title{
AANWINST \\ MAN MET OLIFANTSTAND
}

Het ivoren beeldje dat het Rijksmuseum in 2006 verwierf, stelt - ondanks de onmiskenbare Chinese trekken in het gezicht - een Europeaan voor (afb. 1-3). Hij draagt een lange jas met een kraag en met knoopjes; de soepele stof is bij de heupen aan beide zijden opgenomen zodat het vanaf de ceintuur in zeer symmetrische plooien naar beneden valt. Onder de ceintuur bevindt zich een brede band die met een koord bijeen wordt gehouden. Onder de jas is ook een deel van de kuitbroek zichtbaar. Opmerkelijk zijn de schoenen met hakken en met dezelfde knoopjes als het gewaad.

Afbeeldingen van Europeanen komen in de $18^{\mathrm{e}}$-eeuwse Chinese kunst in verschillende media regelmatig voor. Het gaat daarbij vaak om een uiting van de belangstelling voor exotisme in het algemeen en niet zo zeer om de wens een bepaalde Westerse persoon adequaat weer te geven. Dat dit ook geldt voor het beeldje uit het Rijksmuseum blijkt wel uit de verschillende, tegenstrijdige elemententen die erin zijn samengebracht. Het lange gewaad met de kraag is verwant aan de kleding die Portugese geestelijken droegen die zijn afgebeeld op de Japanse Namban-schermen. ${ }^{1}$ Het lange haar met de krullen is een bijna altijd terugkerend element bij de weergave van Westerlingen sinds de Nederlanders in de $17^{\mathrm{c}}$ eeuw verwoede pogingen deden toestemming te krijgen in China handel te drijven. Het haar zou dus Nederlands genoemd kunnen worden. Met het gezicht wist de beeldsnijder zich blijkbaar weinig raad en dit is Chinees gebleven. De brede band onder de ceintuur dient geen enkel doel en lijkt een verre verwijzing naar een Japanse obi, een brede band van textiel die soms met een grote strik over de kimono werd gedragen. De schoenen met hakken zijn typisch Europees. In zowel Chinese als Japanse weergaven van Europeanen zijn schoenen met hakken vaak geprononceerd weergegeven en in Japan bestond het geloof dat Nederlanders dergelijke schoenen moesten dragen omdat ze geen hielen hadden. Een sluiting aan de bovenzijde van de voet is zeldzaam, maar komt ook voor op een schildering uit 1738 in de collectie van de Vereniging (AK-MAK-1410) waarop een demonenbedwinger en zijn bediende in de gedaante van Westerlingen staan afgebeeld. De achterzijde van het beeld is met uitzondering van de haren, die gestileerd en zeer nauwkeurig zijn weergegeven, nauwelijks bewerkt. Juist deze achterkant vertoont de vaak opgemerkte overeenkomst met figuren in blanc de Chine-porselein. Het beeld vertoont sporen van zwarte en rode polychromie.

Afbeelding 1 Beeld van een Europeaan met een olifantstand in de hand, ivoor met sporen polychromie, hoogte $16,5 \mathrm{~cm}$., China, midden $18^{\text {eeeuw, }}$ inv.nr. AK-RAK-2006-4
De ivoren man is weergegeven als een tribuutbrenger, in de ogen van de Chinezen de best passende rol voor elke buitenlander. Olifantstanden waren in de $18^{\mathrm{c}}$ eeuw een veel gebruikt tribuutgeschenk. Het is bekend dat zich onder de geschenken van de Nederlandse ambassadeur Pieter van Hoorn (gezantschap 1666-1668) vijf olifantstanden bevonden. Vrijwel gelijktijdig zonden de Portugezen een gezantschapowonderdeiding van Manoel de 12:34:49p Saldanha (1667-1670). Saldanha bracht (onder veel meer natuurlijk) tíen access 

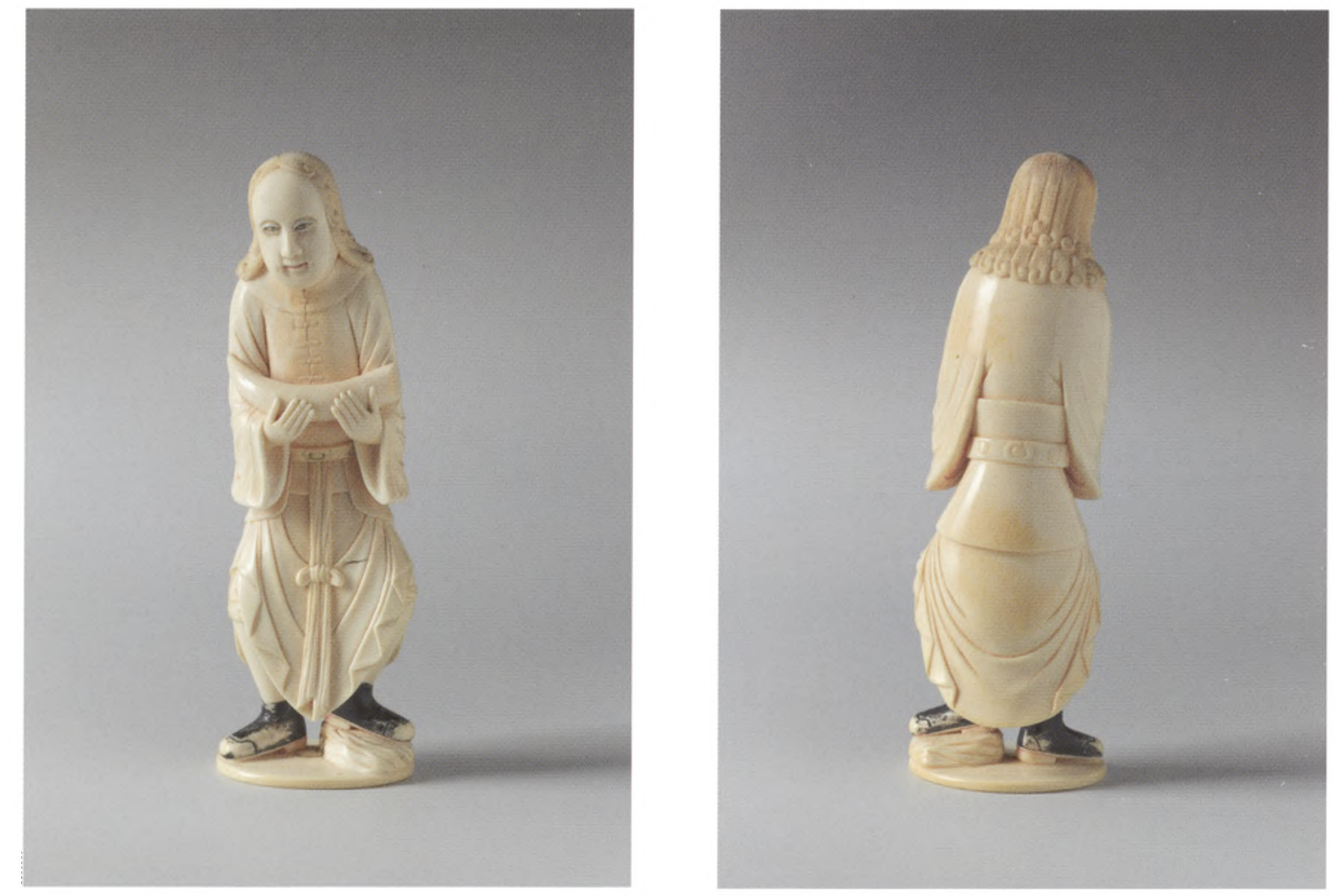

Afbeelding 2 Het beeld van afbeelding 1 , in driekwart

Afbeelding 3 Het beeld van afbeelding $\mathbf{1}$, achterzijde tanden mee voor de Chinese keizer. Ook de Nederlander Vincent Paets bracht bij zijn ambassade in 1685-1687 weer olifantstanden mee, vijf stuks. ${ }^{2}$ Chinese afbeeldingen van tribuutbrengers bevestigen het beeld van de olifantstanden als geëigend geschenk. Op twee grote rolschilderingen uit de Palace Museum collectie (Beijing) dragen Aziatische bedienden van tribuutbrengers enorme olifantstanden (afb. 4-5). ${ }^{3}$ In de Chinese visie op het tribuutbrengen ging het er overigens niet zo zeer om de onderwerping van de buitenlanders tot uitdrukking te brengen, maar juist hun welwillendheid de vreemdelingen op te nemen in hun orde van de kosmos en de wereld. Bij de enorme tanden op de schilderingen steekt het present van de Chinese man uit het Rijksmuseum wat karig af, maar het bijzondere van dit voorwerp is dat het beeld gesneden is uit het materiaal dat de man in zijn hand houdt: de olifantstand. De vorm van de tand is in het beeld zelf ook nog te herkennen. De buiging van de man, iets voorover en iets naar rechts is door de vorm van de tand gedicteerd.

\section{Ivoorsnijden in China}

Olifanten zijn alleen in het grensgebied met Thailand inheems en ivoor werd in China vanouds als een exotisch, kostbaar en gemakkelijk te bewerken materiaal beschouwd. ${ }^{4}$ In de $16^{\mathrm{e}}$ en $17^{\mathrm{e}}$ eeuw kreeg het snijden van figuren een belangrijke impuls door de vraag van Portugese en Spaanse geestelijken. Zij hadden grote behoefte aan beelden voor de kerken die zij in Azië stichtten. Chinese beeldsnijders, voornamelijk in de Zuid-Chinese provincie Fujian (Zhangzhou) slaagden er uitstekend in aan deze vraag te voldoen De $_{6}$ beel- - $_{34: 49 \mathrm{PM}}$ den zijn vaak niet of nauwelijks van Europese exemplaren te onderscheidenccess 
Deze bloei van het beeldsnijden voor buitenlandse kopers bevorderde ook de productie voor de eigen markt. Niet alleen van boeddhistische en taoïstische figuren, maar ook de christelijke voorstellingen - zeer exotisch natuurlijk in Chinese ogen - vonden in China zelf aftrek. ${ }^{5}$ Onder degenen die in de Mingtijd (1368-1644) de goede smaak bepaalden stond snijwerk uit ivoor in minder hoog aanzien dan werk uit jade (geassocieerd met grote ouderdom) en bamboe (rustieke eenvoud). In veel gevallen beschouwden zij de keuze

Afbeelding 4

(linksonder)

Anoniem, hangrol met een voorstelling van tribuutbrengers (detail), kleuren op zijde, $322 \mathrm{x}$ $216 \mathrm{~cm}$., China, 1761, Palace Museum, Beijing, inv.nr. Gu 6274. Overgenomen uit Three Emperors (noot 3)

Afbeelding 5 Anoniem, hangrol met een voorstelling van tribuutbrengers (detail), kleuren op zijde, $365 \mathrm{x}$ $257 \mathrm{~cm}$., China, 18 e eeuw, Palace Museum, Beijing, inv.nr. Gu 6271. Overgenomen uit Treasures from Imperial China (noot 3) voor ivoor voor de voorwerpen waarmee een literaat zich omringde, als vulgair. Ivoor was geschikt voor vermakelijke niemandalletjes.

In de Qing-dyanstie (1644-1911) kwamen er naast Zhangzhou drie centra bij waar veel ivoor werd bewerkt: Kanton, de monding van de Yangzi, en Beijing. Ivoor werd in deze periode in grotere hoeveelheden ingevoerd en ivoren voorwerpen waren in bredere kring geaccepteerd en gewaardeerd. Toch bleef de associatie met 'luchtig vermaak' bestaan. In Kanton richtten de ivoorsnijders zich deels op de vraag van de Westerse kooplieden die vooral onder de indruk waren van hun technische hoogstandjes en de overdaad aan details. Aan het hof van Beijing werkten vanaf 1730 ivoorsnijders die afkomstig waren uit de verschillende centra in het land. Zij bleven steeds een aantal jaren in de keizerlijke werkplaats, leerden de stijl van collega's van elders kennen en keerden dan weer terug naar huis. Thema's en technieken verspreidden zich op die manier over het gehele land. De sterke aandacht voor details en technisch vernuft was zeker niet iets dat alleen de Westerse kooplieden behaagde. Ook veel ivoren voorwerpen die voor het hof werden gemaakt, worden hierdoor gekenmerkt. Het voorwerp diende te verbazen, iets te zijn dat eigenlijk niet gemaakt kon worden, maar toch bestond. Het past in het beeld van luchtig vermaak.
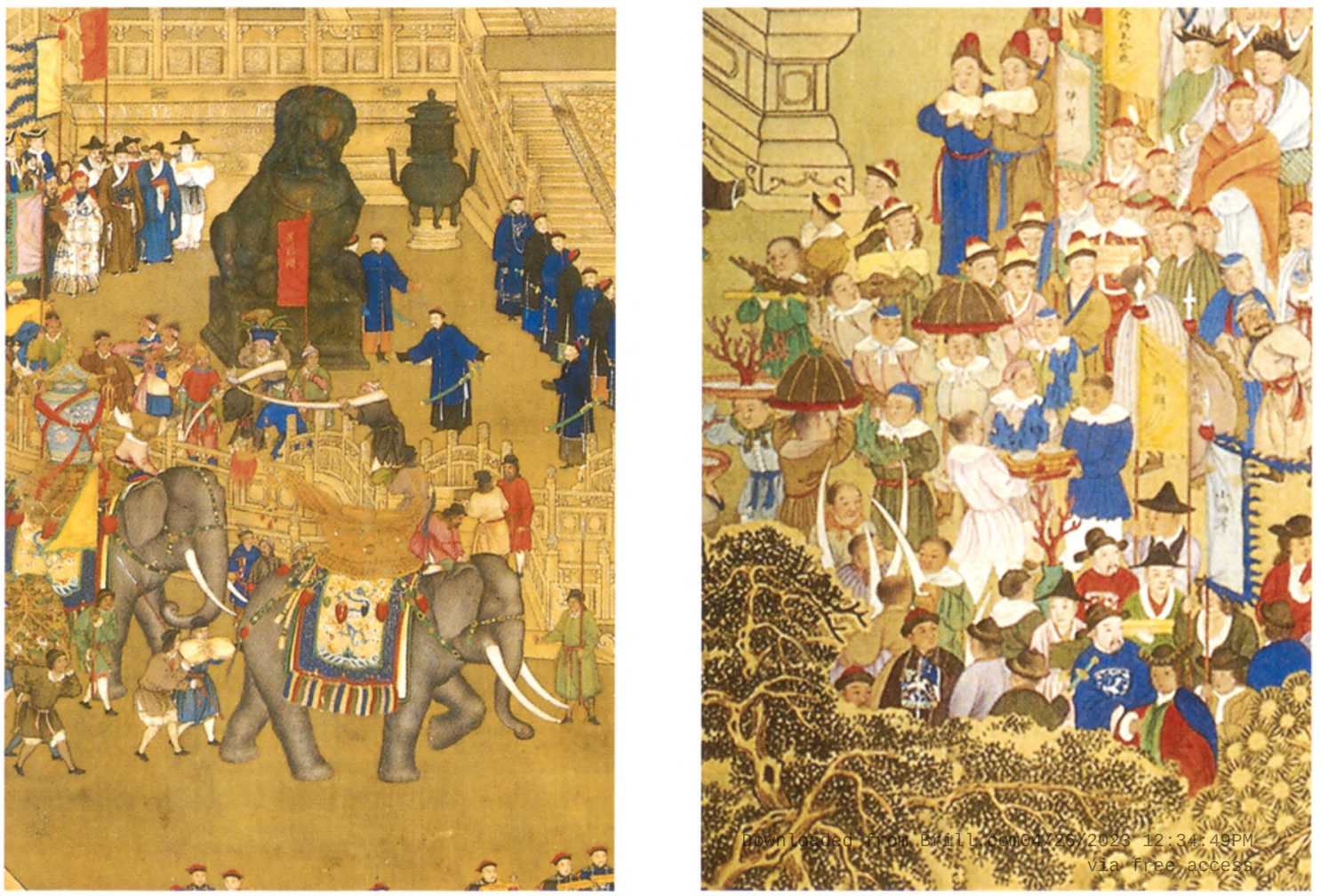
Afbeelding 6

Beeld van een knielende jongen met een haardos in Westerse stijl, ivoor met sporen van polychromie, hoogte $7,6 \mathrm{~cm}$., China, $17^{e} / 18^{\mathrm{e}}$ eeuw. Overgenomen uit Vickers e.a., Ivory (noot 9)

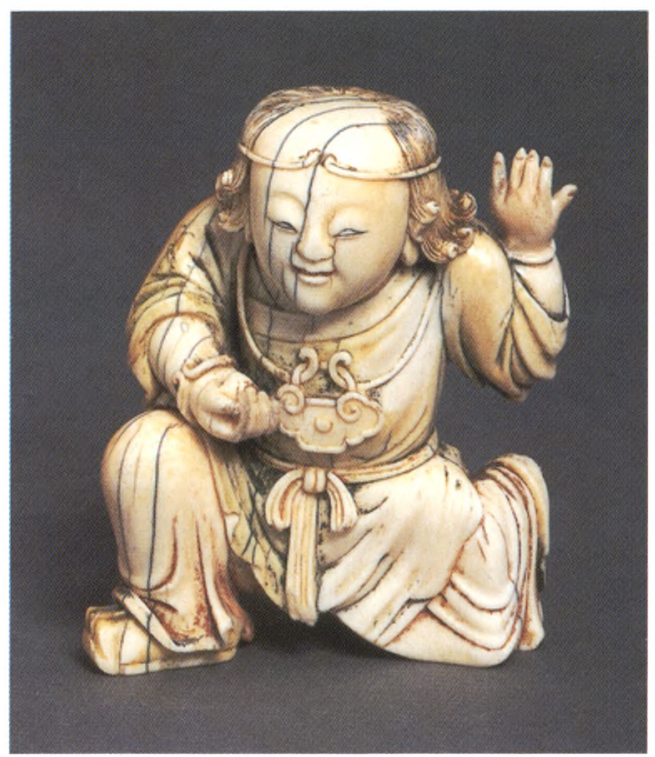

\section{Westerlingen in Chinese kunst en literatuur}

Tegen de achtergrond van de waardering voor ivoor als materiaal ligt de keus voor de Europeaan als onderwerp eigenlijk voor de hand. De Chinees moest geen van beiden te serieus nemen en allebei waren geassocieerd met vermaak en geamuseerde verbazing. Zoals hierboven al is opgemerkt wisselde de nauwgezetheid waarmee Westerlingen in de Chinese kunst werden weergegeven. In Kanton en Beijing had men de grootste kans een Westerling te treffen en hier werden zij soms tamelijk nauwkeurig weergegeven. De belangstelling voor het onderwerp bloeide vanaf de jaren ' 20 van de $18^{\mathrm{e}}$ eeuw op, voornamelijk aan het hof in Beijing en kringen daaromheen, maar ook onder de groeiende groep van welgestelde kooplieden die de leefwijze van de traditionele culturele bovenlaag imiteerde. ${ }^{6}$ Ook nu werden Westerse voorbeelden nauwgezet gekopieerd, maar daarnaast bood het weergeven van Westerlingen de mogelijkheid de fantasie de vrije loop te laten. Een voorbeeld van dit dromen en idealiseren van het voorkomen van een Westerling is te vinden in een passage uit de bekende roman De Droom in de Rode Kamer, uit het midden van de $18^{\mathrm{e}}$ eeuw. ${ }^{7}$ Een van de personages brengt een beeldschoon blond meisje ter sprake dat ze jaren geleden in een zuidelijke haven ontmoet had. 'Een meisje uit het Land van Echter dan Echt dat net vijftien was geworden met een gezicht als de schoonheden op de Westerse schilderijen (...) eigenlijk was ze nog mooier dan de vrouwen op die schilderijen.' Het is interessant hoe positief hier over het Westerse meisje wordt gesproken. Het haar dat ook in het ivoren beeldje uit het museum zo nauwkeurig is weergegeven wordt speciaal vermeld. En, zo wordt de indruk gewekt, het uiterlijk van het meisje is vanzelfsprekend bekend uit Westerse schilderingen. In andere passages in het boek worden verschillende Europese curiositeiten genoemd die te vinden waren in de huizen waar de romanpersonen kwamen: spiegels, brillen, horlogen, klokken. Ze worden slechts terloops vermeld, waaruit opgemaakt kan worden dat Westerse voorwerpen in de welgestelde en luxueuze kringen waarin deze roman zichafspeelt,12:34:49pM gemeengoed waren en geen speciale aandacht verdienden. 
Het beeldje uit het museum is een kleinood dat past in de $18^{\mathrm{e}}$-eeuwse exotische belangstelling in China. Hoewel Nederlanders olifantstanden als tribuutgeschenk naar China brachten, is het zeker geen realistische weergave van een Nederlandse tribuutbrenger. De stijl van het ivoorsnijden in de verschillende Chinese centra was zo sterk onderling beïnvloed dat toeschrijving aan een bepaalde plek niet mogelijk is. Wel kan worden opgemerkt dat de geringe accuratesse in de weergave van de Europeaan níet direct op Kanton of Beijing duidt. Vergelijkbare ivoren beeldjes van Westerlingen zijn zeldzaam. Eén vrijwel identiek exemplaar is bekend en bevindt zich in het Peabody Essex Museum in Salem (MA, USA) ${ }^{8}$ Ook kleinere beeldjes zijn bekend, die nog sterker dan het hier besproken beeld Chinese trekken hebben (afb. 6). Nog evidenter dan het beeld uit het Rijksmuseum zijn deze stukken gemaakt voor Chinese liefhebbers en verleende een enkel Westers element ze een extra exotische aantrekkelijkheid. ${ }^{9}$ Het nieuw verworven beeld past in een groep voorwerpen met voorstellingen van Westerlingen bestemd voor de Chinese markt, ${ }^{10}$ een groep die door deze aanwinst op een fraaie manier versterkt is zodat Chinees exotisme in de toekomstige museumzalen beter tot zijn recht zal kunnen komen.

\section{Noten}

1. In de late Ming-tijd (1368-1644) was China een relatief open samenleving met onder de culturele voortrekkers belangstelling voor geïmporteerde kunstnijverheidsproducten uit Japan. Zie A. Jackson, 'Visual responses: depicting Europeans in east Asia', in: A. Jackson en A. Jaffer (red.), Encounters; the meeting of Asia and Europe 15001800 (tent.cat. Victoria \& Albert Museum), Londen, 2004. Kee Il Choi heeft gewezen op de mogelijke invloed van Namban-schermen op Chinese coromandellakschermen, zie Kee Il Choi Jr., 'Japan and design in early Chinese export art', The Magazine Antiques 158/3 (2000), pp. 336-345.

2. J.E. Wills Jr., Embassies and Illusions; Dutch and Portuguese Envoys to K'ang Hsi, 1666-1687, Cambridge (MA), 1984, appendix E, pp. 253-255. Titsingh nam op zijn ambassade aan het eind van de $18^{\mathrm{e}}$ eeuw geen tanden meer mee, waarschijnlijk waren ze te algemeen geworden. Zie F. Lequin, Titsingh in China (1794-1796); het onuitgegeven journal van zijn ambassade naar Peking, Alphen aan den Rijn, 2005, p. 214.

3. Afgebeeld in Treasures from Imperial China; the Forbidden City and the Royal Danish Court (tent.cat. Christiansborg Palace), Kopenhagen, 2006, cat.nr. 27 en p. 50 en E. Rawski en J. Rawson (red.), China; the three emperors (tent.cat. Royal Academy), Londen, 2005, cat.nr. 83 en p. 180.

4. Zie voor dit onderwerp C. Clunas, Chinese Carving, Londen, 1996 en de catalogus W. Watson (red.) Chinese Ivories from the Shang to the Qing (tent.cat. Oriental Ceramic Society en British Museum), Londen, 1984.

5. Clunas, Op.cit. (noot 4), p. 18. De schrijver van een gids met bezienswaardigheden in Beijing uit 1635 vermeldt dat op een bepaalde markt in de stad 'images of Jesus from the Western Ocean' worden verkocht.

6. J. Waley-Cohen, 'Diplomats, Jesuits and Foreign Curiosity', in: E. Rawski en J. Rawson (red.), Op.cit. (noot 3), pp. 180-182. L. Littrup, 'The Chinese View of Europe 1600-1850', Treasures from Imperial China, op.cit. (noot 3), pp. 278-285.

7. De schrijver Cao Xueqin (ca. 1715-1763) was een verarmde telg uit een voornaam geslacht dat voorheen nauwe banden met het hof had gehad. Hij was een man van goede smaak en wist waarover hij schreef. De roman is pas in 1791 gepubliceerd, de laatste hoofdstukken, waaruit hier ook wordt geciteerd zijn mogelijk door een ander, na zijn dood geschreven. W. L. Idema, 'Canon, Clocks and Clever Monkeys: 
(red.), Development and decline of Fukien province in the $17^{\text {th }}$ and $18^{\text {th }}$ centuries, Leiden etc., 1990, pp. 468-469. Het navolgende citaat is door mij vertaald overgenomen uit het artikel van Idema.

8. Encounters op.cit. (noot 1), nr. 16.8.

9. M. Vickers e.a., Ivory; a history and collector's guide, Londen, 1987 no. 14;

D. Howard \& J. Ayers, China for the West. Deel II, Londen/New York, 1978, nrs. 684, 686-688; Watson, Op.cit (noot 4), nrs 134-135 en 141 voor dezelfde objecten als in Howard \& Ayers; R. Soame Jenyns, Chinese Art. Deel III. nr. 99 voor een plaque met de voorstelling van een Europeaan; in het Rijksmuseum bevindt zich eveneens een fraaie plaque met de voorstelling van drie Europeanen in een sloep, NG 1994-12.

10. K. Ruitenbeek, 'Westerlingen in de achttiende-eeuwse Chinese kunst', Aziatische Kunst 20/4 (1990), pp. 10-22.

\section{VAN HALM \& VAN HALM \\ FINE ORIENTAL CERAMICS LONDON}

Deelnemers aan de 7de Internationale Salon van de Oude Keramiek, 27 april - 1 mei 2007, Kasteel Edingen, Edingen, België.

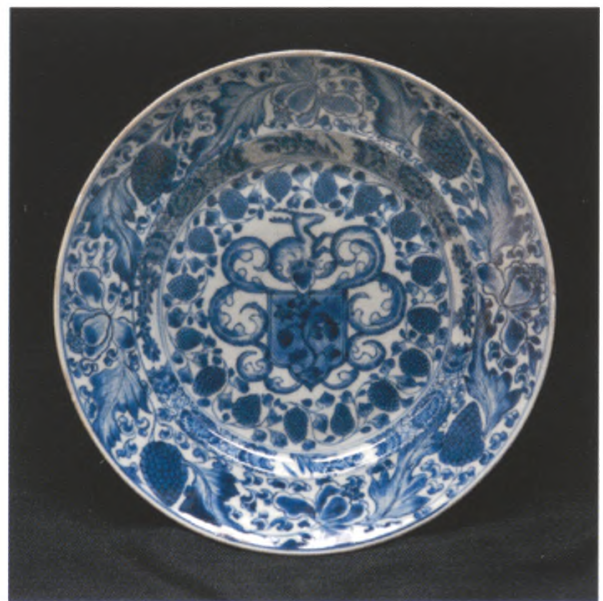

Een zeldzaam blauwwit bord gedecoreerd met een Europees familiewapen. China, Iste kwart 18 de eeuw, Ø $22 \mathrm{~cm}$.

Voor inlichtingen email: allard.vanhalm@planet.nl 